\title{
CLINICOPATHOLOGICAL FEATURES ASSOCIATED WITH IMMUNOHISTOCHEMISTRY LOSS OF MISMATCH REPAIR PROTEIN MLH1 IN ENDOMETRIOID ENDOMETRIAL CARCINOMA

\author{
D. de Freitas ${ }^{1,2}$, F. N. Aguiar ${ }^{1}$, C. Anton 1 , C. E. Bacchi3 ${ }^{3}$ J.P. Carvalho ${ }^{1,4}$, F.M. Carvalho ${ }^{2^{*}}$ \\ 1 Instituto do Cancer do Estado de São Paulo, Faculdade de Medicina da Universidade de São Paulo, São Paulo, SP, Brazil \\ 2 Department of Pathology, Faculdade de Medicina da Universidade de São Paulo, São Paulo, SP, Brazil \\ ${ }^{3}$ Consultoria em Patologia, Botucatu, SP, Brazil \\ ${ }^{4}$ Department of Obstetrics and Gynecology, Faculdade de Medicina da Universidade de São Paulo, São Paulo, SP, Brazil
}

\section{Objectives}

The aim of this study was to assess the association between DNA mismatch repair protein MLH1 status and classical prognostic factors in patients with endometrioid endometrial carcinoma.

\section{Methods}

We studied 47 consecutive patients aged 37-88 (61.34 \pm 10.52$)$ with confirmed diagnosis of endometrial carcinoma of endometrioid type. The tumors were classified according the WHO 2014 criteria and graded using the FIGO system. The following pathological characteristics were analyzed: tumor size $(\mathrm{mm})$, percentage of myometrial infiltration, presence of microcystic, elongated, and fragmented (MELF) pattern of myoinvasion, percentage of tumoral infiltrating lymphocytes (TILs), and lymph-vascular space invasion (LVSI). Deficiency of MLH1 protein was defined as complete loss of nuclear expression within tumor cells in the presence of positive internal controls in lymphocytes and/or stroma. The chi-square test and the MannWhitney $U$ test were used to compare the groups with and without MLH1 loss.

\section{Conclusions}

Loss of MLH1 was associated with bigger tumors, MELF pattern of myoinvasion, and positive lymph nodes. Tumors with MLH1 loss tend to have more myometrial infiltration, more LVSI, and more TILs, although it did not reach a statistical level of significance. The presence of higher percentage of TILs, as well MLH1 loss itself, may indicate immunotherapy susceptibility for therapies targeting the programmed cell death (PD)/programmed cell death ligand-1 (PD-L1) immune checkpoint pathway.

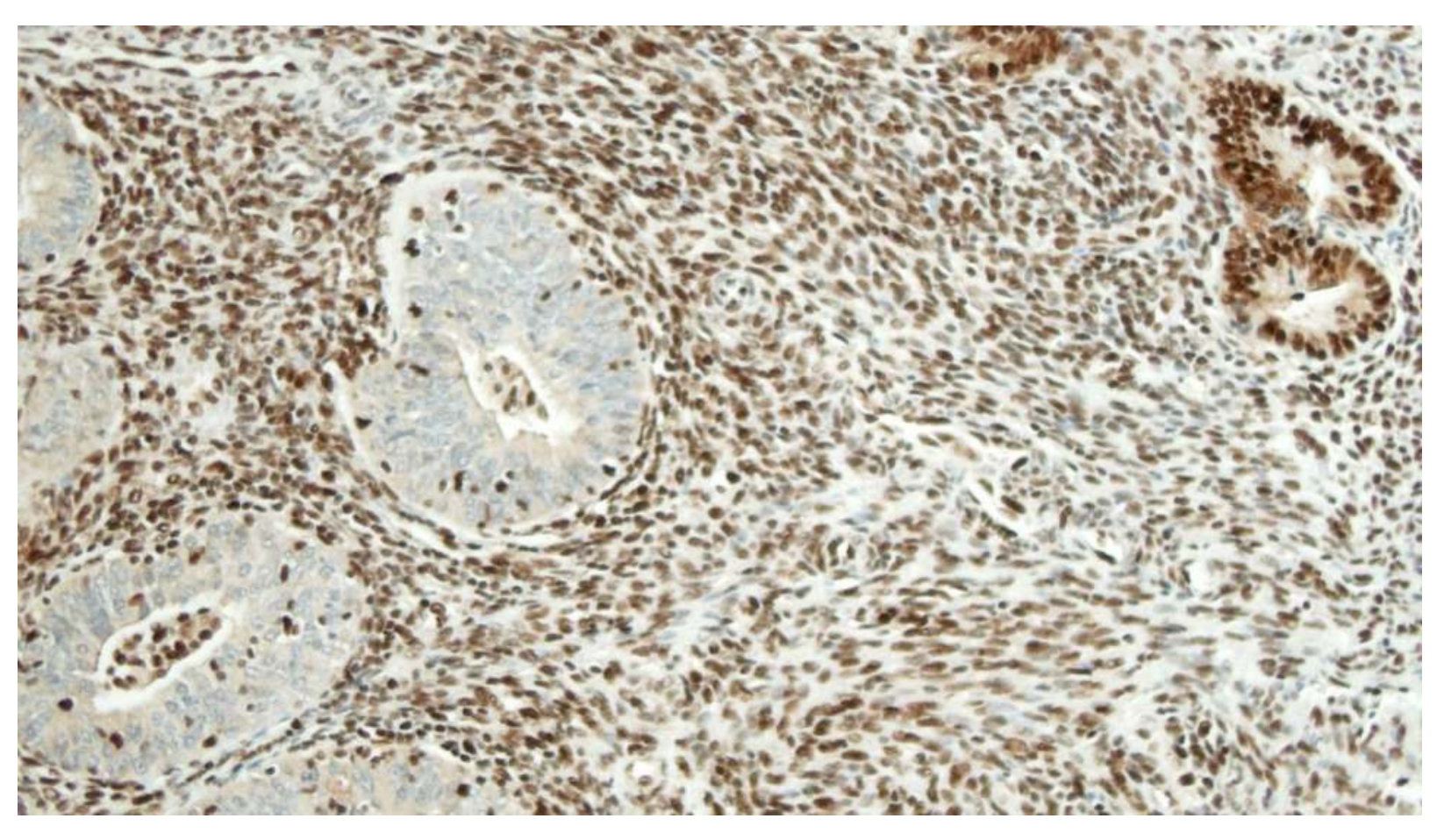

Figure 1 - Loss of MLH1 stain in neoplastic glands. Note positive stain in normal stroma and glands, as well as in intraepithelial lymphocytes

\section{Results}

Loss of MLH1 was observed in 18/47 (38.3\%) patients. Age of patients did not differ between MLH1-negative and MLH1positive tumors $(61.2 \pm 11.0$ years and $61.4 \pm 10.4$ years, respectively). The comparison of characteristics of the tumors with and without MLH1 loss is summarized in Table 1.

Table 1 - Clinicopathological features of endometrioid endometrial carcinomas according MLH1 immunohistochemistry status

\begin{tabular}{|c|c|c|c|}
\hline Features & MLH1-loss & MLH1-positive & $p$ \\
\hline Total of patients & 18 & 29 & \\
\hline \multicolumn{4}{|l|}{ FIGO } \\
\hline 1 & $5(41.7 \%)$ & $16(80.0 \%)$ & 0.03 \\
\hline II/III & $7(58.3 \%)$ & $4(20 \%)$ & \\
\hline \multicolumn{4}{|c|}{\begin{tabular}{l|l|l} 
ESMO-ESGO-ESTRO & \\
\end{tabular}} \\
\hline Low risk & $0(0 \%)$ & $5(25 \%)$ & 0.08 \\
\hline Intermediate risk & $2(16.7 \%)$ & $0(0 \%)$ & \\
\hline High-intermediate & $4(33.3 \%)$ & $8(40 \%)$ & \\
\hline risk & & & \\
\hline High risk & $6(50 \%)$ & $7(35 \%)$ & \\
\hline \multicolumn{4}{|c|}{\begin{tabular}{|l|l} 
Histological grade & \\
\end{tabular}} \\
\hline $1 / 2$ & $16(88.9 \%)$ & $21(72.4 \%)$ & 0.18 \\
\hline 3 & $2(11.1 \%)$ & $8(27.6 \%)$ & \\
\hline \multicolumn{4}{|l|}{ Tumor size } \\
\hline Range (median) & $20-70 \mathrm{~mm}(35 \mathrm{~mm})$ & $8-48 \mathrm{~mm}(27 \mathrm{~mm})$ & 0.02 \\
\hline \multicolumn{3}{|c|}{ Myometrial invasion } & 0.23 \\
\hline \multicolumn{4}{|c|}{ Myometrial invasion } \\
\hline$<50 \%$ & $5(35.7 \%)$ & $13(52 \%)$ & 0.33 \\
\hline$>50 \%$ & $9(64.3 \%)$ & $12(48 \%)$ & \\
\hline \multicolumn{4}{|l|}{ LVSI } \\
\hline Yes & $11(73.3 \%)$ & $15(57.7 \%)$ & 0.15 \\
\hline No & $4(26.7 \%)$ & $11(42.3 \%)$ & \\
\hline \multicolumn{4}{|l|}{ MELF } \\
\hline Yes & $7(50 \%)$ & $5(20 \%)$ & 0.05 \\
\hline No & $7(50 \%)$ & $20(80 \%)$ & \\
\hline \multicolumn{4}{|c|}{\begin{tabular}{|l|l|} 
TILs & \\
\cline { 2 - 3 }
\end{tabular}} \\
\hline range (median) & $0-90 \%(40 \%)$ & $0-90 \%(10 \%)$ & 0.13 \\
\hline \multicolumn{4}{|c|}{\begin{tabular}{l|l} 
Node & \\
\end{tabular}} \\
\hline Positive & $4(33.3 \%)$ & $1(5 \%)$ & 0.03 \\
\hline Negative & $8(66.7 \%)$ & $19(95 \%)$ & \\
\hline
\end{tabular}

